\title{
Power Generation by Offshore Wind Turbines: An Overview on Recent Research and Developments
}

\author{
SUDIP BASACK* ${ }^{*}$ SHANTANU DUTTA DIPASRI SAHA GOUTAM DAS \\ Elitte College of Engineering, Affiliation: MAKA University of Technology, \\ Kolkata 700113, INDIA
}

\begin{abstract}
Wind energy is one of the most sustainable and renewable resources of power generation. Offshore Wind Turbines (OWTs) derive significant wind energy compared to onshore installations. With the established phenomena that the wind speed has been high and consistent in offshore regions, the OWTs are likely to generate more electricity compared to the onshore ones. Design and installation of OWTs require sophisticated technology due to critical ocean environment to meet the safety and serviceability criteria. This necessitates in-depth understanding of power efficiency, mechanical operations and dynamic force distributions, together with the structural and foundation stabilities. This paper presents an intensive review of the existing knowledge on each of these diversified study areas. It is observed the subject is still under development with a significant number of unsolved problems. A critical analysis and the research directions on the relevant investigations have also been included in the paper.
\end{abstract}

Key-Words: - Dynamic force, Lift and Drag, Monopile, Ocean environment, Power efficiency, Wind energy

Received: April 12, 2021. Revised: September 29, 2021. Accepted: October 17, 2021. Published: November 15, 2021.

\section{Introduction}

As an alternative to the conventional energy sources such as thermal and hydropower, the renewable energy resources initiate several benefits including environmental preservation and integrated energy usage. Various natural sources available to generate renewable energy include the utilization of sunlight, wind, rain, tides, waves, biomass, geothermal energy, etc. In the last 5 years, the renewable energy has contributed to about $19-25 \%$ of total energy usage and consumption worldwide, thereby highlighting the socio-economic benefits and effective utilization of public funds [1-3]. At least 30 nations around the world produce significant proportions of their total electricity generation through renewable energy and such proportion is in an ascending trend [4].

A consistent and higher wind speed in offshore environment is exploited to generate electricity through Offshore Wind Turbine (OWT). In the global scenario, the total offshore wind power capacity has been recently recorded above $35 \mathrm{GW}$ [5]. However, design and installation of OWTs are still in the early stage of research and development, from the viewpoint of both technological feasibility and cost effectivity [6]. Unlike the offshore oil drilling rigs, a typical OWT requires appropriate structural components to withstand the static and dynamic forces generated during its operation. An appropriate design and installation technique to capture the wind energy and converting the mechanical rotation into electrical power, together with numerous control mechanisms, necessitates adequate engineering judgements with scientific understanding of the entire system [7].

A typical OWT consists of electrical, mechanical and supporting civil infrastructural components, as portrayed in the schematic diagram in Figure 1 below.

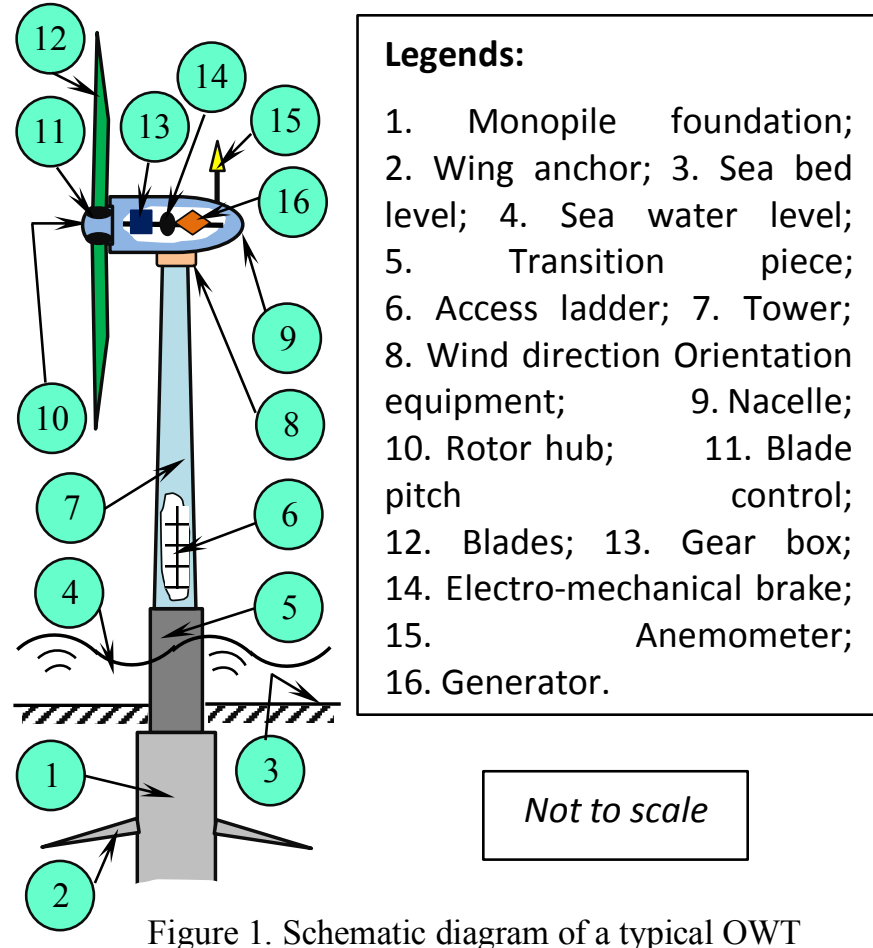

In this paper, an in-depth review and critical analysis of existing knowledge on the different study aspects of design and installation of OWTs. This includes adequate evaluation of power efficiency, mechanical and dynamic operations and structural and foundation stability. The advancements of the subjects in last few decades have mostly been covered. Limitations of the studies and scope for future research have also been included in the paper. Detailed review on each of the study areas have been sequentially presented below. 


\section{Power Efficiency}

About $2 \%$ of the solar energy falling on the earth surface is converted into kinetic energy in form of wind. Thus, the wind energy is free, abundant in nature and causes least pollution, although the distribution of wind energy, both across the earth surface and vertically through the atmosphere, have been uneven [8].

OWTs are designed in a way that it can utilize the maximum wind energy available in surrounding area. Hence, the height of turbine and the sizes of blades are optimized to capture maximum wind energy to work effectively and efficiently. The ratio of the output electrical energy to the kinetic energy in the wind is defined as the 'wind efficiency' or 'power coefficient'. Mathematically, this is expressed by:

$$
\eta_{w}=\frac{E_{e}}{E_{k}} \times 100 \%
$$

where, $\eta_{w}$ is the wind efficiency, while $E_{e}$ and $E_{k}$ are the output electrical energy and the kinetic energy of the wind, respectively.

This non-dimensional parameter is obviously a function of the wind speed, apart from various other components of the OWT. The operating wind speed to continue the turbine function has been found to commence from $4-5 \mathrm{~m} / \mathrm{s}$, while the maximum power output is obtained at around $15 \mathrm{~m} / \mathrm{s}$. At significantly high wind speeds of about $25 \mathrm{~m} / \mathrm{s}$, the OWTs shut down. A modern wind turbine produces electricity at a power coefficient of $70-85 \%$ [9].

From classical theory of fluid mechanics [10], the total power in wind stream is given by the following correlation:

$$
P_{\text {total }}=0.5 \rho_{a} A_{b}^{t} v^{3}
$$

where, $P_{\text {total }}$ is the total power, $\rho_{a}$ is the mass density of the wind, $A_{b}^{t}$ is the total blade area and $\mathrm{v}$ is the wind speed.

The power efficiency of a wind turbine has been defined as the ratio of output electrical power to the wind power. Mathematically,

$$
\eta_{p}=\frac{P_{\text {output }}}{P_{\text {total }}} \times 100 \%
$$

where, $\eta_{p}$ is the maximum power efficiency and $P_{\text {output }}$ is the maximum power output from the OWT. In accordance with Betz's law, no turbine can capture more than $16 / 27$ of the kinetic energy in wind. Thus, the optimum value of $\eta_{p}$ is limited to $59.3 \%$ which is commonly known as Betz limit; in reality, the value varies in the range of $35-45 \%$ [11].

As discussed above, the OWTs cannot operate at a very low wind speed due to insufficient torque. Conversely, significantly high wind speed initiates inability of operation due to possible damages to its structural and mechanical components. The minimum possible wind speed to ensure operation is termed as 'cut-in speed' which is usually $4 \mathrm{~m} / \mathrm{s}$. When the wind speed exceeds this limit, the power output is observed to increase nonlinearly till an optimum speed is attained, termed as 'rated wind speed', which generally varies in the range of $12-14 \mathrm{~m} / \mathrm{s}$. The power output remains constants beyond this speed, till a maximum speed termed as 'cutout speed' is reached, which is approximately $25 \mathrm{~m} / \mathrm{s}$. The OWT does not operate beyond this maximum wind speed A typical variation of power output versus wind speed is portrayed in Figure 2 [12].

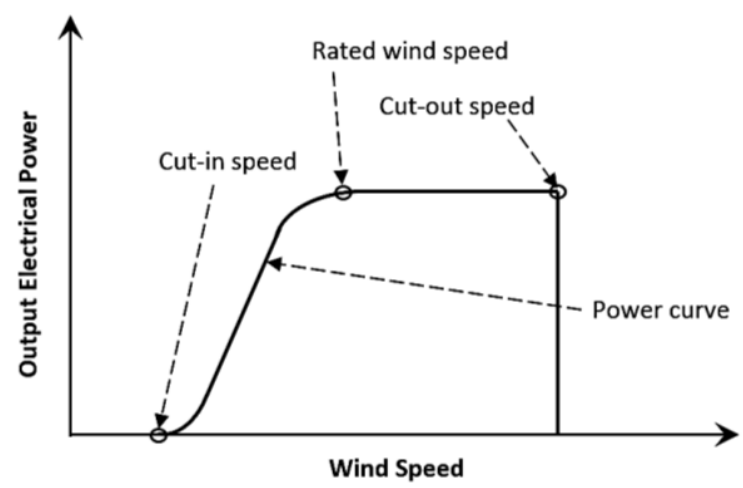

Figure 2. A typical power curve

Using a power curve, it is also possible to plot the power coefficient as a function of wind speed. The in-situ environment demands optimization of power output. As observed, the output power is being multiplied several times for a small increase in the rotor diameter. Hence, an optimization in design technique is required to enhance the efficiency of OWT to meet the global demand. A typical plot showing the same is depicted in Figure 3 [13].

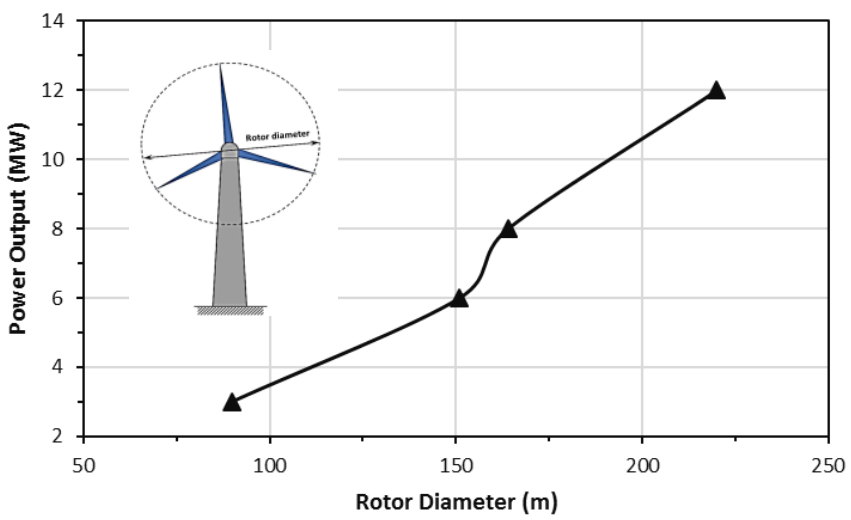

Figure 3. Influence of rotor diameter increase on power output

Global application and demand of wind energy is increasing by leaps and bounds. The worldwide power capacity obtained from available wind energy is depicted in Figure 4 [14].

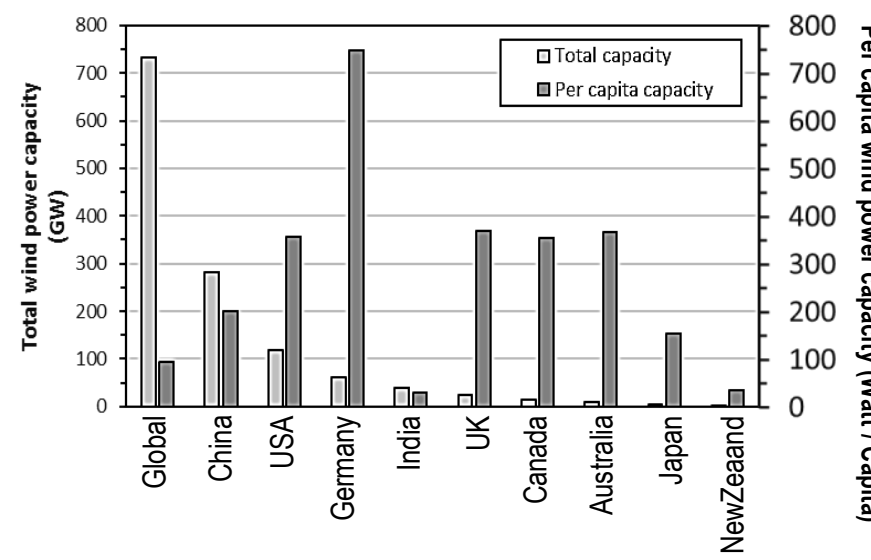

Figure 4. Wind power capacity in different countries in 2020 
The OWTs adopt undersea cables to transmit electricity to the power grid. To ensure a strong power transmission system, gas insulated line installed in a tunnel is preferred. Its high-power transmission capability of $2000 \mathrm{MW}$ at $400 \mathrm{kV}, 3000$ $\mathrm{MW}$ at $500 \mathrm{kV}$ and $4000 \mathrm{MW}$ at $800 \mathrm{kV}$ per three phase system serves the purpose. The high voltage direct current system is preferred over AC-cables. Conventional line commutated converter or less mature voltage source converter is unsuitable for connection to OWT [15].

\section{Mechanical Operation and Dynamic Force Distribution}

OWT is a specially designed equipment which transforms the wind kinetic energy into rotational energy, thereby producing electricity. Since the wind thrust is directly imparted on the OWT blades, an indepth analysis of the blade aerodynamics by means of a typical airfoil profile is essential for adequate mechanical design [16]. An optimum design should ensure a maximum lift with a minimum drag at a given angle of airflow, based on aerodynamic principle, apart from the associated pitching moment over the blade of the airfoil. Referring to Figure 5 below, the upper surface of the airfoil always has a larger velocity with minimum static pressure, while the same is reversed in case of the bottom surface. This initiates a lift force in the airfoil. The other important geometrical aspects of the airfoil influencing the aerodynamic characteristics are the trailing and leading edges, chord line and the angle of wind attack.

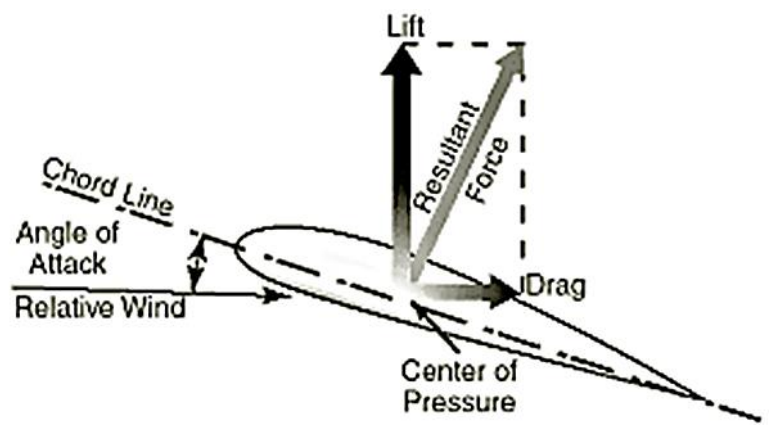

Figure 5. Aerodynamic forces acting on a typical airfoil

Theoretically, the mathematical expressions for the lift and drag forces in case of a typical airfoil is given by [17]:

$$
\begin{aligned}
& F_{L}=0.5 \rho A_{e} C_{L}\left(v-v_{t}\right)^{2} \\
& F_{D}=0.5 \rho A_{e} C_{D}\left(v-v_{t}\right)^{2}
\end{aligned}
$$

where, $F_{L}$ and $F_{D}$ are the lift and drag forces, $C_{L}$ and $C_{D}$ are the coefficients of lift and drag forces respectively, $A_{e}$ is the frontal area of the airfoil normal to the wind direction and $v_{t}$ is the speed of the airfoil. More streamlined the blade objects are, the lesser are the value of $C_{D}$. For a typical OWT, the term $v_{t}$ can be approximated as follows:

$$
v_{t}=\omega \frac{D}{2}
$$

where, $\omega$ and $D$ are the angular velocity and diameter of the rotor, respectively. Using the above correlations, the total power generation given in Eq. (2), above is modified for a vertical axis OWT, conventionally termed as drag-based wind turbine, as,

$$
P_{\text {total }}=0.5 \rho A_{e} C_{D} v_{t}\left(v-v_{t}\right)^{2}
$$

In case of a horizontal axis OWT, which is a lift-based wind turbine, the total power generation is given by:

$$
P_{\text {total }}=0.5 \rho A_{e}\left(\sqrt{v^{2}+v_{t}^{2}}\right)\left(C_{L} v v_{t}-C_{D} v_{t}^{2}\right)
$$

Schematic diagrams of typical horizontal and vertical axes OWTs are shown in Figure 6.

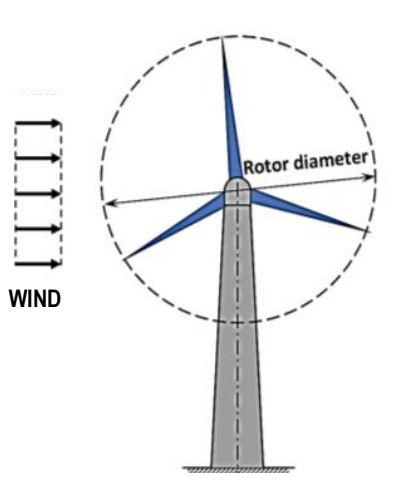

(a) (b)

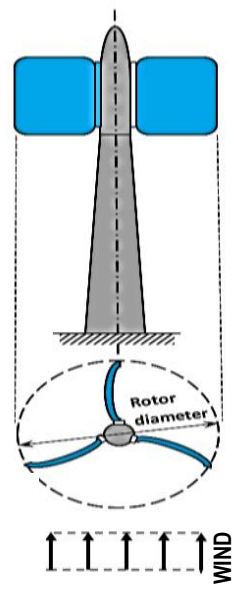

Figure 6. Schematic diagram of OWT:

(a) horizontal axis, and (b) vertical axis

Majority of OWTs have a horizontal axis of rotation which can be either upwind or downwind. In an upwind turbine, the wind hits the blades before the tower, while the latter is opposite. In both the cases, the tower is equipped with a yaw drive and motor to turns the nacelle windward. These turbines are typically either two- or three-bladed and operate at high blade tip speeds. Vertical axis OWTs, on the other hand, can be drag-based which have rotors with solid vanes or lift-based that have tall, vertical airfoil. They are typically small wind turbines which can operate independently of wind direction, which is a major advantage for urban applications where wind direction can change rapidly.

As discussed earlier, a typical OWT transforms the kinetic energy associated with the wind into rotational energy by the torque generated utilizing the aerodynamic rotor blades and by power and speed control techniques. Through electro-mechanical energy conversion done through a generator, the electricity is transmitted to the power grids. From the viewpoint of mechanical operation, the OWTs can be classified as either which are regulated by stall (with active stall as the performance index) or in the form of pitch regulated. The former regulation is taken care of by adopting optimum design of blades such that airfoil does not produce significantly large forces at higher wind velocities. The pitch regulation, on the other hand, is carried out by utilizing pitching mechanism in the hub of OWTs which twist the blade by its self-axial means [18]. A schematic diagram of the mechanical set-up inside the OWT is provided in Figure 7.

With the constant alteration in the wind velocities, the primary requirement of OWT is the quick pitching of blades to the optimum angle to control the imparted torque to ensure the capture of maximum energy or self-protect. 


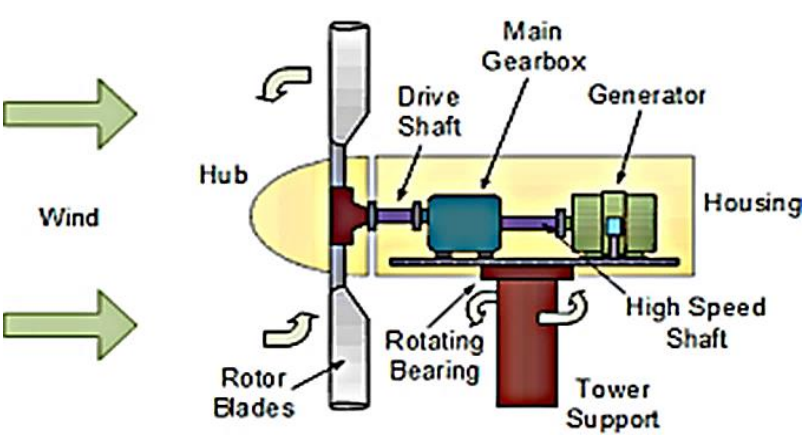

Figure 7. Schematic diagram: interior details of an OWT

OWTs are subjected to significantly high level of multiaxial stresses due to uneven aerodynamic and hydrodynamic loads which should be accounted for the design of its mechanical components. Due to high frequency cyclic and dynamic loads, the natural frequencies of the OWT together with its structural and foundation components and their damping characteristics are considered in the design procedure. The wind energy produces rotational energy to the rotor. Such rotation is likely to initiate high frequency of cyclic loading to the structural and mechanical components of OWT. When the frequency of such cyclic loading coincides with the natural frequency of the OWT as a whole, resonance is likely to be produced, which is expected to produce severe damage to all the vital components of the turbine. Hence, the appropriate design technique is incorporated that such undesirable situation does not arise at all. Several standard software are available to take care of the complex design requirement of OWT, including FAST, Orca Flex, QBlade, etc. [19-21].

It is worth mentioning that OWT are exposed to ocean environment and influenced by marine lives. Thus, appropriate condition-based maintenance methods and procedures have been adopted worldwide to minimize the maintenance costs and increase the reliability. Some of these techniques are summarized in Table 1 [22].

\section{Structure and Foundation Stability}

The design life of OWT is usually 50 years, although the foundations are designed for longer life span. The tower should be capable of withstanding static, dynamic and cyclic loads and their critical combinations, hence an appropriate fatigue analysis is essential [23].

The foundation design is much dependent on the sea water depth which is classified as shallow $(<30$ $\mathrm{m})$, transitional $(30-50 \mathrm{~m})$ and deep $(>50 \mathrm{~m})$ [24]. The economic aspects of foundation vary with depth of sea water and construction technique adopted; the foundation cost is almost one third of the overall project cost in OWT. While selecting the foundation type, the influence of wind, marine current, tidal range, waves, construction technique, installation, operation and disassemble, etc. are taken into consideration [3].

From existing literature, the OWT foundations are broadly categorized as floating type and bottom fixed. The former one functions in a similar way like
Table 1. Methods for analysis of OWT components: maintenance and conditional monitoring

\begin{tabular}{|c|c|c|c|c|c|c|}
\hline Components & $\mathrm{a}$ & $\mathrm{b}$ & $\mathrm{c}$ & $\mathrm{d}$ & $\mathrm{e}$ & $\mathrm{f}$ \\
\hline $\begin{array}{c}\text { Strategy } \\
\text { Vibration } \\
\text { analysis }\end{array}$ & $\mathrm{N}$ & $\mathrm{Y}^{\mathrm{g}}$ & $\mathrm{Y}^{\mathrm{h}}$ & $\mathrm{Y}^{\mathrm{j}}$ & $\mathrm{Y}^{\mathrm{k}}$ & $\mathrm{Y}$ \\
\hline $\begin{array}{c}\text { Torsional } \\
\text { analysis }\end{array}$ & $\mathrm{N}$ & $\mathrm{N}$ & $\mathrm{N}$ & $\mathrm{Y}^{\mathrm{n}}$ & $\mathrm{Y}^{\mathrm{p}}$ & $\mathrm{N}$ \\
\hline $\begin{array}{c}\text { Acoustic } \\
\text { emission }\end{array}$ & $\mathrm{N}$ & $\mathrm{Y}^{\mathrm{q}}$ & $\mathrm{Y}^{\mathrm{r}}$ & $\mathrm{Y}^{\mathrm{s}}$ & $\mathrm{Y}^{\mathrm{t}}$ & $\mathrm{N}$ \\
\hline $\begin{array}{c}\text { Temperature } \\
\text { analysis }\end{array}$ & $\mathrm{N}$ & $\mathrm{N}$ & $\mathrm{Y}^{\mathrm{u}}$ & $\mathrm{N}$ & $\mathrm{N}$ & $\mathrm{N}$ \\
\hline Oil analysis & $\mathrm{Y}^{\mathrm{v}}$ & $\mathrm{Y}^{\mathrm{w}}$ & $\mathrm{N}$ & $\mathrm{N}$ & $\mathrm{N}$ & $\mathrm{N}$ \\
\hline $\begin{array}{c}\text { Ultrasonic } \\
\text { test }\end{array}$ & $\mathrm{Y}^{\mathrm{x}}$ & $\mathrm{Y}^{\mathrm{z}}$ & $\mathrm{N}$ & $\mathrm{N}$ & $\mathrm{N}$ & $\mathrm{N}$ \\
\hline
\end{tabular}

Notes:

[1] OWT components: (a) Tower, (b) Blade, (c) Bearings, (d) Shaft, (e) Gearbox, and (f) Generator.

[2] Y: Always done; N: Not adopted.

[3] Testing techniques: (g) active flow control over blade; (h) measuring vibrations at high frequency rates; (j) new signal processing methods; $(\mathrm{k})$ vibration content of the drive train components; (m) electromagnetic forces; (n) rotor whirl modes; (p) flexible multi-body simulation; (q) by considering the blade as variable mass and stiffness with influences of gravity and centrifugal stiffening; (r) dynamic load effects and interfaces of the detailed bearing model; (s) mounting two sensors in radial directions on each rotor; (t) drive train kinematics; (u) thermal sensors; (v) synthetic formulations; (w) oil compatibility specifications for paints, lacquers, sealants and bearing materials; (x) ultrasonic nondestructive test with liquid dampers; (z) ultrasonic testing;

the bottom fixed type foundation, which has been the floating oil and gas platforms, which depends entirely on the mooring and anchoring systems [14].more popular, are classified as: (a) gravity type, (b) monopile, (c) suction caisson, and (d) multi-pod (tripod or jacket system). Generally, gravity type is used in shallow water, whereas monopile and suction caisson are adopted in transitional water. Multi-pod system are preferred in deep water [25].

Gravity type foundation is suitable for soil having high bearing capacity such as stiff clay or rock. It is adopted as a replacement of monopiles which cannot be driver into such stiffer soil strata. Despite its acceptance in stiffer soil, large base area requirement together with significant cost of construction and installation, it become obsolete [26]. A typical sketch showing the salient features of a gravity type foundation is depicted in Figure 8.

Monopile type foundations, preferred in transitional water depth, revealed that maintenance cost of materials has been relatively less. However, the installation of monopile using heavy instruments like jack-up barges adversely affect the marine ecosystem [27]. Figure 9 depicts a schematic sketch of a typical monopile foundation for OWT.

The suction caisson type foundation is mostly preferred for OWT because of its cost effectivity and rapid installation procedure. Since no major equipment is necessary for installation, it is also environment friendly. The shape of this foundation is like an inverted bucket, while about $50 \%$ curtailment of steel weight may be achieved over monopile foundation [28]. A sketch of suction caisson is shown in Figure 10. 


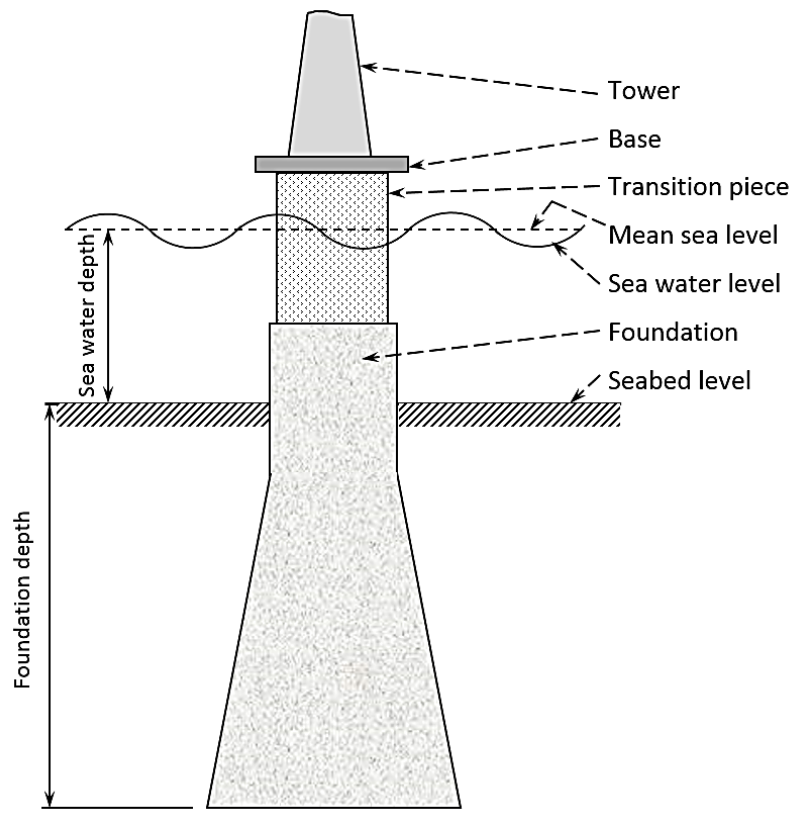

Figure 8. Schematic diagram: gravity type foundation

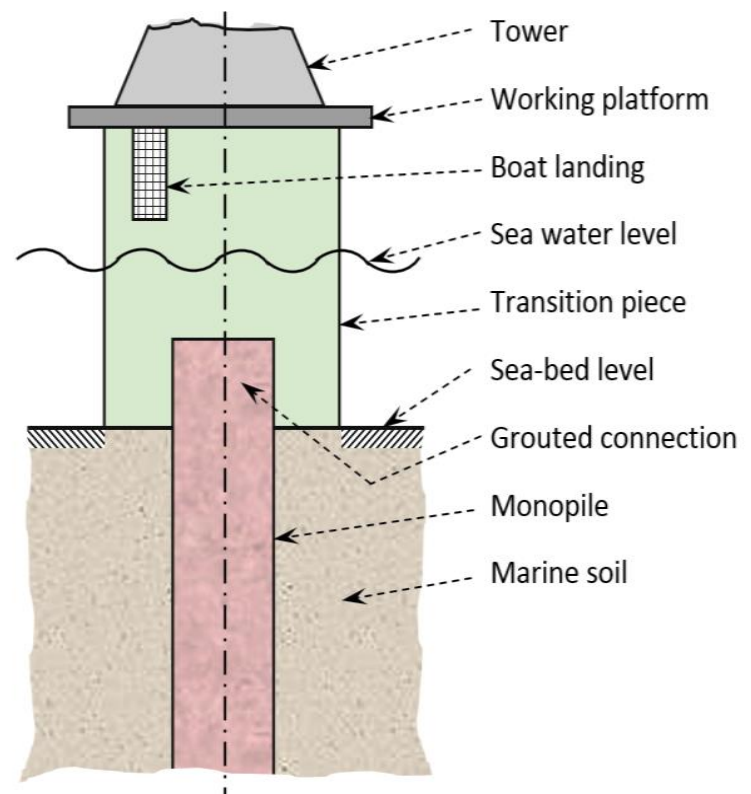

Figure 9. Schematic diagram: monopile foundation

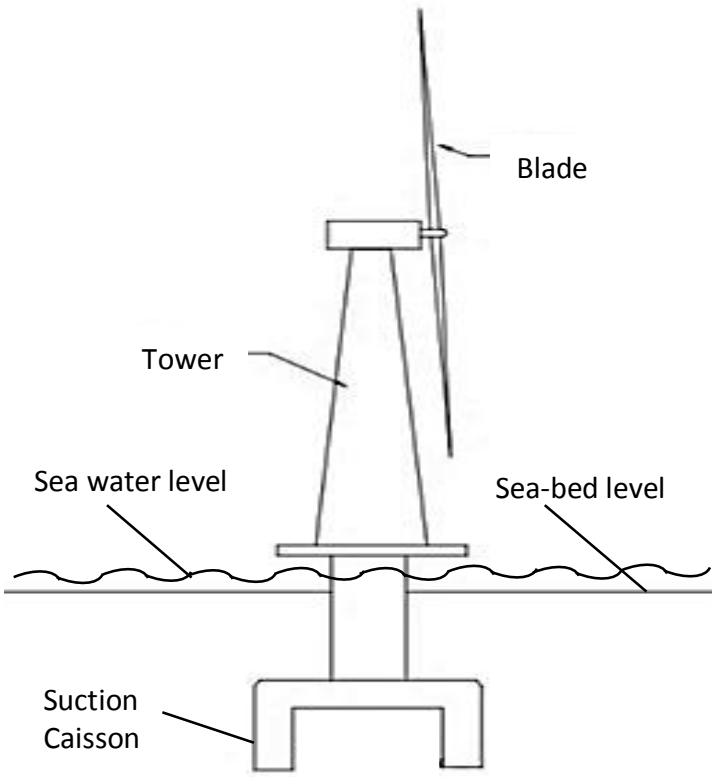

Figure 10. Schematic diagram: caisson foundation
Multi-pod type foundation used in low bearing capacity soil is effective in deep water. In this case, steel framed structure used as substructure are embedded in the soil, whose base rests on monopile and suction caisson. The steel frames are installed underground at relatively shorter depth. This lightweight structure reduces the construction and installation cost. Compared to monopile and suction caisson, the multi-pod provides more stability and stiffness during hurricanes and typhoons [29]. Figure 11 portrays a sketch of this type of foundation.

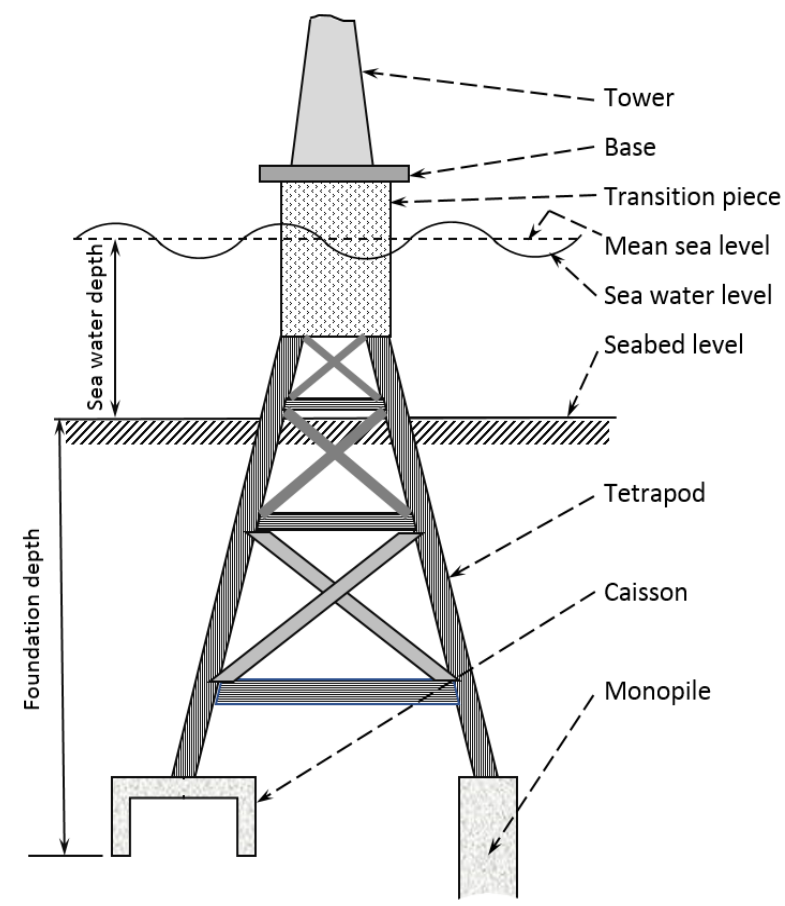

Figure 11. Schematic diagram: multi-pod type foundation

Each type of the above described foundation has its own advantages and disadvantages. The merits and demerits of different types of OWT foundations have been summarized in Table 2 below.

Table 2. Merits and demerits of various OWT foundations

\begin{tabular}{|l|c|c|c|c|}
\hline $\begin{array}{c}\text { Foundation } \\
\text { type } \\
\text { Critical } \\
\text { factors }\end{array}$ & a & b & c & d \\
\hline $\begin{array}{c}\text { Seawater } \\
\text { depth }\end{array}$ & Shallow & Transition & $\begin{array}{c}\text { Transi- } \\
\text { tion }\end{array}$ & Deep \\
\hline $\begin{array}{c}\text { Soil bearing } \\
\text { capacity }\end{array}$ & High & $\begin{array}{c}\text { Medium to } \\
\text { low }\end{array}$ & $\begin{array}{c}\text { Medium } \\
\text { to low }\end{array}$ & Low \\
\hline $\begin{array}{l}\text { Impact on } \\
\text { Environment }\end{array}$ & Low & High & Low & $\begin{array}{c}\text { Mo- } \\
\text { derate }\end{array}$ \\
\hline $\begin{array}{l}\text { Stability and } \\
\text { durability }\end{array}$ & Low & Moderate & $\begin{array}{c}\text { Mode- } \\
\text { rate }\end{array}$ & High \\
\hline $\begin{array}{l}\text { Construction } \\
\text { cost }\end{array}$ & High & Moderate & Low & Low \\
\hline $\begin{array}{l}\text { Note: } \\
\text { [1] Foundation type - (a) Gravity, (b) Monopile, (c) Suction } \\
\text { caisson, and (d) Multi-pod. } \\
\text { [2] For most cases, mono-pile foundation is the usual preference } \\
\text { over the other foundations owing to the offshore environment. } \\
\text { [3] Tripod and multi-pod foundation is a new technique and } \\
\text { research is under progress on its suitability and efficiency. }\end{array}$
\end{tabular}


The influence of cyclic loading on foundations are often quite critical [30-31]. During design of OWT foundation, the input loading parameters should be ascertained from appropriate aerodynamic and hydrodynamic analyses. Based on the site condition, adequate choice of foundation type is made. Thereafter choosing necessary foundation geometries, the safety factors are estimated. This should be followed by serviceability checks and finally evaluating the stress distributions for structural design and estimation of fatigue life. An iterative trial and error technique is usually adopted [32-33]. Failure of OWT foundation usually occurs due to inadequate safety factor against critical combinations of design loads or excessive displacement of foundation top jeopardizing its serviceability criteria. To ensure adequate design, structural and foundation health monitoring is essential [34].

\section{Critical Analysis \& Research Directives}

The available literature relevant to OWTs has been broadly classified into three categories related to electrical, mechanical and civil engineering. So far as the OWT power efficiency is concerned, the existing theories relevant to wind power and the electrical efficiency have been described. The optimal efficiency is derived within a specific range of wind speed. The total electrical power increases with rotor diameter. In a global perspective, China was found to generate maximum wind energy, while Germany was found to be highest in per capita. In the section of mechanical operations and dynamic force distribution, the existing correlations for lift and drag forces have been presented, and the interior details with mechanical components of OWT have been presented. Appropriate testing strategies for various mechanical components has been described. In the next section, the structural and foundation stability has been presented and comparison of different types of foundations for OWT has been made. The relative proportion of contributions in various sectors have been portrayed in Fig. 12(a).

OWT analysis and design aiming towards optimized power generation is a challenge to the engineers because of the complexity of ocean environment. The electrical, mechanical and structural/foundation components should be designed adequately under critical conditions. Moreover, corrosive degradation of material strength and stiffness due to sustained exposure to saltwater should be taken into consideration. The appropriate risk analysis and management is crucial as well. The occupational health and safety management in the offshore wind sector is likely to initiate health risk of the workers, commencing from minor sickness due to sustained adverse environmental exposure, to acute injuries and mortalities. Apart from the risk during erection, installation, servicing, maintenance and dismantling, malfunction of electrical, mechanical or structural components might be fatal [35].
The research directives necessitates focused investigation on diversified unsolved problems including in-depth analysis of aerodynamic phenomena under external conditions, such as wind flow distribution on the rotor plane for various turbine configurations, improved quantification of design loads, innovative materials, optimized designs, verification of structural strength, and reliability of the OWT components, etc.

Based on the above observations and inspired by the available literature, the authors propose a flowchart of execution of OWT from design stage till dismantling stage, as highlighted in Figure 12 [36]. This figure consists of adequate risk assessment and monitoring in each of the phases of execution, associated with iterative steps consisting of major and minor loops. As observed, the proposed methodology is essentially a continuous process.
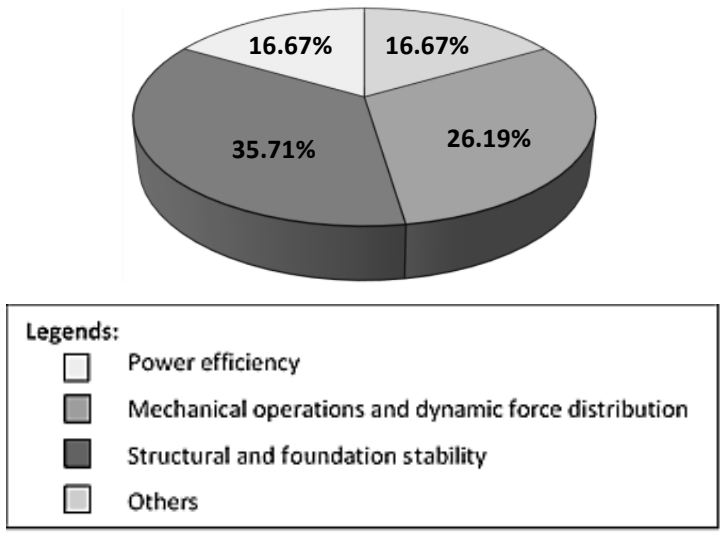

(a)

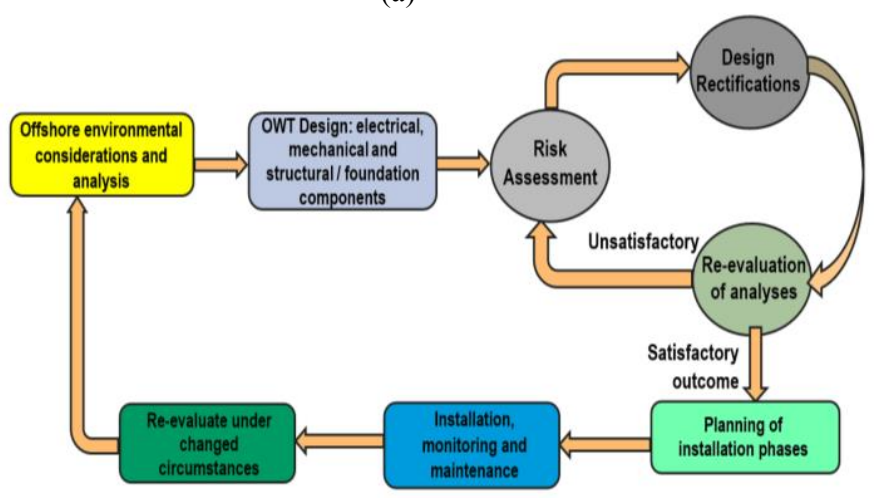

(b)

Figure 12. (a) Pie chart of literature review, and (b) proposed flowchart of execution

In the recent few decades, significant developments have been in the field of alternative power generation, including wind energy sector [37-40]. The paper presents in-depth review to three important research aspects related to OWT. These are most relevant to the design and development and the information given are helpful to practicing engineers and scientists working in similar study fields. The presentations herein are succinct, rigorous and novel.

For several years, the first author is involved in cuttingedge research in the area of offshore pile foundation analysis and design [30-31, 41-42]. The research outcomes have direct relevance with the OWT foundations. In this paper, the authors have attempted a generalized review covering various engineering aspects of OWT. 


\section{Conclusions}

This paper presents a brief overview on the existing studies carried out on offshore wind turbines. The power efficiency, mechanical operation and force distributions, structural and foundation stability analysis are the study aspects that are covered herein. Based on these reviews, critical analysis and appropriate research directives have also been presented.

The study indicates that OWTs operate at certain minimum and maximum wind speeds, beyond which the turbines do not function. The maximum power efficiency has been found to be below $60 \%$, based on Betz theory. Significant rise in the output power occurs with increase in rotor diameter. The wind power capacities in different countries around the globe have also been summarized.

So far as the dynamic force distribution and mechanical operations are concerned, it was found that the rotation of blades takes place by means of aerodynamic principle of airfoil. The standard correlations for lift and drag forces for moving turbines have been presented. It was found that the operating forces for horizontal and vertical axes OWTs were different. The interior details of a typical nacelle have been presented. The mechanical design techniques of different dynamic components have been presented.

Stability of OWTs have been found to be largely dependent on the choice of appropriate foundation to satisfy the safety and serviceability criteria. The merits and demerits of different foundation types have been briefly presented. It has been observed that the structural and foundation design of OWT required complex analysis of multiaxial static, dynamic and cyclic loads originated primarily by wave, wind and current in the ocean environment.

A critical analysis of the existing literature indicated several important considerations to be undertaken right from the planning phase till the installation and finally the dismantling stages. A flowchart of risk analysis has also been proposed.

\section{Acknowledgements}

The authors thankfully acknowledge the infrastructural supports received from Pinnacle Educational Trust, Kolkata, India, during execution of the study.

\section{References:}

[1] Omar, E., Haitham, A. R. and Frede, B. Renewable energy resources: current status, future prospects and their enabling technology, Renewable and Sustainable Energy Reviews. Vol. 39, pp. 748-764, 2014, doi: 10.1016/j.rser.2014.07.113

[2] Ziaei, S. M., The impacts of household social benefits, public expenditure on labour markets, and household financial assets on the renewable energy sector, Renewable Energy, Vol. 181, pp. $51-58,2022$.
[3] Raktate, T. and Choudhary, R. Design of monopile foundation for offshore wind turbine, E3S Web of Conferences, 170, 010, 1-6, 2020, https://doi.o rg/10.1051/e3sconf/202017001024

[4] Mathiesen, B. V., Lund, H., Connolly, D., Wenzel, H., Ostergaard, P. A., Möller, B., Nielsen, S., Ridjan, I., Karnoe, P., Sperling, K. and Hvelplund, F. K., Smart energy systems for coherent $100 \%$ renewable energy and transport solutions, Applied Energy, Vol. 145, pp. 139-154, 2015.

[5] Global Wind Energy Council. Global Wind Report 2021 https://gwec.net/wpcontent/uploads/2021/03/GWEC-Global-WindReport-2021.pdf

[6] Roggenburg, M., Esquivel-Puentesa, H. A., Vaccaa, A., Evans, H. V., Garcia-Bravo, J. M., Warsinger, D. M., Ivantysynova, M. and Castilloa, L., Technoeconomic analysis of a hydraulic transmission for floating offshore wind turbines, Renewable Energy, Vol. 153, pp. 1194-1204, 2020.

[7] Caliao, N. D. Dynamic modelling and control of fully rated converter wind turbines, Renewable Energy, Vol. 36, No. 8, pp. 2287-2297, 2011.

[8] Wind Energy Factsheets, Center for Sustainable Systems, University of Michigan, 2021, https://css.umich.edu/factsheets

[9] Lee, J. C. Y. and Fields, M. J., An overview of windenergy-production prediction bias, losses, and uncertainties, Wind Energy Science, Vol. 6, No. 2, pp. 311-365, 2021.

[10] Munson, B. R. and Young, D. F., Fundamentals of Fluid Mechanics, John Wiley \& Sons, 1994.

[11] Betz, A., Introduction to the Theory of Flow Machines, D. G. Randall, Trans., Oxford: Pergamon Press, 1966.

[12] Neill, S. and Hashemi, M. R., Fundamentals of Ocean Renewable Energy, Academic Press, 2018.

[13] Wiser, R. and Bolinger, M., 2016 Wind Technologies Market Report, Lawrence Berkeley National Laboratory, U.S. Department of Energy, Washington, DC, DOE/GO-102917-5033, 2017.

[14] Renewable capacity statistics 2021, International Renewable Energy Agency (IRENA), Abu Dhabi.

[15] Koch, H., Grid connection of offshore wind farms, Proceedings, IEEE Power \& Energy Society General Meeting, Vancouver, Canada, pp. 1-5, 2013.

[16] McCormick, Barnes W., Aerodynamics, Aeronautics, and Flight Mechanics, Wiley, United Kingdom, 1995.

[17] Schmitz, S., Aerodynamics of Wind Turbines: A Physical Basis for Analysis and Design. Hoboken: Wiley, 2019.

[18] Camm, E. H., M. R. Behnke, O. Bolado, et al., Characteristics of wind turbine generators for wind power plants, IEEE Power \& Energy Society General Meeting, pp. 1-5, 2009.

[19] Jonkman, B. J. and Jonkman, J. M., FAST v8.16.00abjj User's Guide, NREL, Golden, USA, p. 58, 2016.

[20]Orcina. OrcaFlex. Available online: https://www.orcina.com/orcaflex 
[21]Qblade. Available online: http://www.qblade.org

[22] Ren, Z., Verma, A. S., Li, Y., et al., Offshore wind turbine operations and maintenance: a state-of-the-art review, Renewable and Sustainable Energy Reviews, 144, 110886, 2021.

[23]Det Norske Veritas A. S., 2010. OS-J101 Design of Offshore Wind Turbine Structures, DNV-OSJ101, 2013.

[24] Oh, K. Y., Nam, Y., Ryu, M. S., et al., A review of foundations of offshore wind energy convertors: current status and future perspectives, Renewable and Sustainable Energy Reviews, Vol. 88, pp. 16-36, 2018.

[25] Lavanya, C. and Kumar, N. D., Foundation types for land and offshore sustainable wind energy turbine towers, Proceedings, E3S Web of Conferences, Vol. 184, No. 01094, 2020.

[26] Dolores, E. M., López-Gutiérrez, J. S. and Negro, V., Gravity-based foundations in the offshore wind sector, Journal of Marine Science and Engineering, Vol. 7, No. 3, pp. 64, 2019.

[27] Trojnar, K., Simplified design of new hybrid monopile foundations for offshore wind turbines, Ocean Engineering, Vol. 219, 108046, 2021.

[28] Liu, B., Zhang, Y., Ma, Z., et al. Design considerations of suction caisson foundations for offshore wind turbines in Southern China, Applied Ocean Research, Vol. 104, 102358, 2020.

[29] $\mathrm{Wu}, \mathrm{X} ., \mathrm{Hu}, \mathrm{Y} ., \mathrm{Li}, \mathrm{Y}$., et al., Foundations of offshore wind turbines: a review, Renewable and Sustainable Energy Reviews, Vol. 104, pp. 379-393, 2019.

[30] Basack, S. and Nimbalkar, S., Numerical solution of single pile subjected to torsional cyclic load, International Journal of Geomechanics, Vol. 17, Issue 8, https://doi.org/10.1061/(ASCE)GM.19435622.0000905

[31] Basack, S. and Nimbalkar, S., measured and predicted response of pile groups in soft clay subjected to cyclic lateral loading, International Journal of Geomechanics, Vol. 18, Issue 7, https://doi.org/10.1061/(ASCE)GM.19435622.0001188

[32] Arany, L., Bhattacharya, S., Macdonald, J. and Hogan S. J., Design of monopiles for offshore wind turbines in 10 steps, Soil Dynamics \& Earthquake Engineering, Vol. 92, pp. 126-152, 2017.

[33] Basack, S., Design recommendations for pile subjected to cyclic load, Marine Georesources and Geotechnology, Vol. 33, Issue, 4, pp. 283287, http://dx.doi.org/10.1080/1064119X.2013.778378

[34] Chen, J. and Gilbert, R. B., Offshore pile system model biases and reliability, Georisk:
Assessment and Management of Risk for Engineered Systems and Geohazards, Vol. 11, No. 1, pp. 55-69, 2020.

[35] Charles, J., Kumar, R., Kumar, D. V., Baskar, D., Arunsy, B. M., Jenova, R. and Majid, M. A., Offshore wind energy status, challenges, opportunities, environmental impacts, occupational health, and safety management in India, Energy \& Environment, Vol. 32, No. 4, pp. 565-603, 2020.

[36] Basack, S., Loganathan, M. K., Goswami, G. and Khabbaz, H., Saltwater intrusion into coastal aquifers and associated risk management: critical review and research directives, Journal of Coastal Research, 2021 (In Press).

[37] Wang, X., Niu, W. and Gu, W., Applied systems theory: wind turbine output power prediction based on wind energy utilization coefficient, International Journal of Circuits, Systems and Signal Processing, Vol. 14, 2020, pp. 356-366.

[38] He, Q., Harmonics of double-fed wind power system with grid-tied dual-PWM converter, International Journal of Circuits, Systems and Signal Processing, Vol. 14, 2020, pp. 743-750.

[39] Lafont, F., Balmat, J. F., Join, C. and Fliess, M., First steps toward a simple but efficient model-free control synthesis for variable-speed wind turbines, International Journal of Circuits, Systems and Signal Processing, Vol. 14, 2020, pp. 1181-1191.

[40] Ruda, M., Boyko, T. and Mesa, C. L., Computer simulation of the influence of wind power plants on the compartments of the complex landscape system by the method of life cycle assessment, Engineering World, Vol. 1, 2019, pp. 34-50.

[41] Nimbalkar, S., Punetha, P., Basack, S. and Mirzababaei, M., Piles subjected to torsional cyclic load: numerical analysis, Frontiers in Built Environment, Vol. 5, Art. 24, 2019, https://doi.org/10.3389/fbuil.2019.00024

[42] Basack, S., Goswami, G. and Nimbalkar, S., Analytical and numerical solutions to selected research problems in geomechanics and geohydraulics, WSEAS Transactions on Applied and Theoretical Mechanics, Vol. 16, pp. 222-231, 2021, $\mathrm{http} / / / \mathrm{dx}$. doi.org/10.37394/232011.2021.16.25

\section{Conflict of Interest Statement}

The authors declare that there is no conflict of interest in this paper.

\section{Authors' Contributions}

Sudip Basack has done overall supervision and execution; Shantanu Dutta, Dipasri Saha and Gautam Das conducted literature survey, analysis, writing and revisions.

\section{Creative Commons Attribution License 4.0 (Attribution 4.0 International, CC BY 4.0)}

This article is published under the terms of the Creative Commons Attribution License 4.0

https://creativecommons.org/licenses/by/4.0/deed.en_US 